\title{
HIV/AIDS-Related Knowledge among Secondary School Students in Bangladesh: A Cross-Sectional Study
}

\author{
Md. Nazmul Huda ${ }^{1}$, Dr. Asm Amanullah ${ }^{2}$ \\ ${ }^{1}$ Department of Sociology and Anthropology, Green University of Bangladesh, Dhaka, Bangladesh; ${ }^{2}$ Department of Sociology, Uni- \\ versity of Dhaka, Dhaka, Bangladesh. \\ Email: nazmulsoc2008@gmail.com
}

Received July $23^{\text {rd }}, 2013$; revised August $23^{\text {rd }}, 2013$; accepted August $30^{\text {th }}, 2013$

Copyright (C) 2013 Md. Nazmul Huda, Dr. Asm Amanullah. This is an open access article distributed under the Creative Commons Attribution License, which permits unrestricted use, distribution, and reproduction in any medium, provided the original work is properly cited.

\begin{abstract}
Background and Aim of the Study: HIV/AIDS is best viewed as a major epidemic which poses serious challenges to mankind on a global scale. The aim of this study was to assess the HIV/AIDS-related knowledge among secondary school students in Bangladesh and investigate the association between secondary school students' socio-demographic characteristics and their level of knowledge about HIV/AIDS. Methods: Following multistage random sampling technique, a total of 384 students aged 11 - 17 years were sampled from eight secondary schools and interviewed through a predesigned semi-structured questionnaire. Data analysis was done at three stages including descriptive statistics, bivariate analyses, and multivariate logistic regression. Results: The findings of the study revealed that more than half $(55.26 \%)$ of the students were above 14 years of age and their ages ranged from 11 to 17 years. This study also found that around three-fourths of the students $(75.78 \%)$ watched television. With regard to knowledge, this study demonstrated that around two-fifths of the students (36.98\%) had very good knowledge about HIV/AIDS and their main sources of HIV/AIDS information were television, newspaper, radio, textbooks, and teachers. The bivariate results of the study indicated that students' age, gender, type of school, household income, fathers' and mothers' literacy, and watching television were significantly associated with level of knowledge about HIV/AIDS. In addition, students' age, mothers' literacy, and watching television were found as the significant predictors of knowledge about HIV/AIDS. Watching television was documented as the best single predictor. Conclusion: The results of the study strengthen the assumption that there is an influence of students' socio-demographic characteristics upon their knowledge about HIV/ AIDS. Moreover, this study suggests that more information on HIV/AIDS should be included in the textbooks of secondary school students in Bangladesh to enhance their knowledge about the taboo subject.
\end{abstract}

Keywords: HIV/AIDS; Knowledge; Secondary School Students; Socio-Demographic Factors

\section{Introduction}

Since its emergence in 1981, the HIV/AIDS pandemic, which poses a serious challenge to mankind, without doubt, has become one of the most serious infectious diseases [1]. Again, HIV infection, which has increased among young people aged 15 - 24 years, is a development problem [2-4]. Recent UNAIDS report on the global AIDS epidemic estimates that globally, 34.0 million [31.4 million - 35.9 million] people were living with HIV at the end of 2011. It also asserts that an estimated $0.8 \%$ of adults aged 15 - 49 years worldwide are living with HIV [2]. In 2011, it is estimated that almost 5 million people are living with HIV in South, South-East and East
Asia combined. Five countries (namely India, Indonesia, Myanmar, Nepal, and Thailand) account for the majority of HIV infections [2]. Bangladesh is geographically vulnerable to HIV/AIDS due to its close proximity to India, Myanmar, Nepal, and Thailand having various degrees of the epidemic [5]. In 2011 the National AIDS and STD Program (NASP) in Bangladesh informed that there were 445 newly reported cases of HIV and 251 new AIDS cases, out of which 84 people had died [6]. Thus, the cumulative number of reported HIV cases to date in Bangladesh stands at 2533, AIDS cases at 1101 and death toll at 3258 [7]. However, the actual number of HIV/ AIDS cases is still unknown due to limited and incom- 
plete surveillance facilities [8].

Though knowledge regarding HIV/AIDS is an important part of HIV/AIDS prevention [9], this has not been examined among secondary school students in Bangladesh. However, a very few notable studies have been carried out to examine the knowledge about HIV/AIDS among the adolescents in Bangladesh. For example, Uddin et al. (2010) [10] documented the Bangladeshi adolescents' level of knowledge about HIV/AIDS. The findings of their study revealed that adolescents had fair level of knowledge about HIV/AIDS. Again, the results of the studies of Shirin and Ahmed (2007) [11] and Rahman et al. (2009) [12] showed that respondents had average knowledge regarding HIV/AIDS. Moreover, Khan (2002) [13] examined the HIV/AIDS knowledge among the female adolescents of four divisions namely Dhaka, Chittagong, Rajshahi, and Sylhet in Bangladesh. The results of his study indicated that only one (17\%) in six adolescents had ever heard of AIDS. Almost similar finding was found in the study accomplished by Rahman et al. (1998) [14] among the Commercial Sex Workers (CSWs) in Bangladesh-18 percent of CSWs had heard of AIDS. Furthermore, to evaluate the rural people's knowledge about AIDS in Bangladesh, Fulton et al. (1998) [4] did a study on them. The findings of their research demonstrated that of the total population of 3834 women and 2272 men, only $7.4 \%$ (256) of the women and $16.0 \%$ (364) of the men had heard of the disease AIDS. Thus, the results of the majority researches mentioned above showed poor or average knowledge about HIV/AIDS since most of these studies had been carried out among those who were mostly uneducated or unaware of the disease. This cross-sectional study, therefore, identified the knowledge related to HIV/AIDS among secondary school students in Bangladesh.

Some previous studies on HIV/AIDS suggest that knowledge about HIV/AIDS varies by socio-demographic factors of the respondents. For instance, Lal et al. (2000) [15] studied the association between gender and type of students and knowledge about HIV/AIDS. The results of their study revealed that boys' and urban students' knowledge was better than that of girls and rural students respectively. Again, the results of the study carried out Wong et al. (2008) [16] showed that older and urban respondents and those having higher level of income demonstrated greater level of knowledge about HIV/AIDS. Furthermore, Tee and Huang (2009) [17] examined the factors such as age, education, and monthly income that influence respondents' knowledge about HIV/AIDS. Therefore, the following research hypothesis guided this study.

Secondary school students' knowledge about HIV/ AIDS varies by their socio-demographic characteristics such as age, gender, type of school, education, household income, fathers' literacy, mothers' literacy, watching television, and religiosity.

\section{Methods (Figure 1)}

\subsection{Participants}

A cross-sectional questionnaire survey was conducted among the students of grade six to ten in some educational institutions in Bangladesh. The heads of the sampled institutions were duly informed and their consent was taken before approaching the respondents. From the selected sampled schools, 384 students from grade six to ten were surveyed using self-administered questionnaire and all students voluntarily participated in this study.

\subsection{Procedure}

A standard set of questionnaire was distributed among the students. Before administering the questionnaire, the nature of the study was explained to the students and they were assured of the anonymity of the survey and secrecy of his/her personal answers. The survey was carried out during the regular school hours. Students were made to sit apart and asked not to communicate with each other during the administration of the questionnaire so as to encourage honest responses. After collecting the completed questionnaires, students were thanked for their participation.

The present study focused on secondary school students' knowledge about HIV/AIDS by analyzing the strength of their agreement or disagreement with a variety of twelve statements related to HIV/AIDS knowledge. These twelve items initially had a four-point response options (strongly agree, agree, strongly disagree and disagree) which were later dichotomized into " $0=$ false" and " $1=$ true" for the purpose of data analysis. The sum

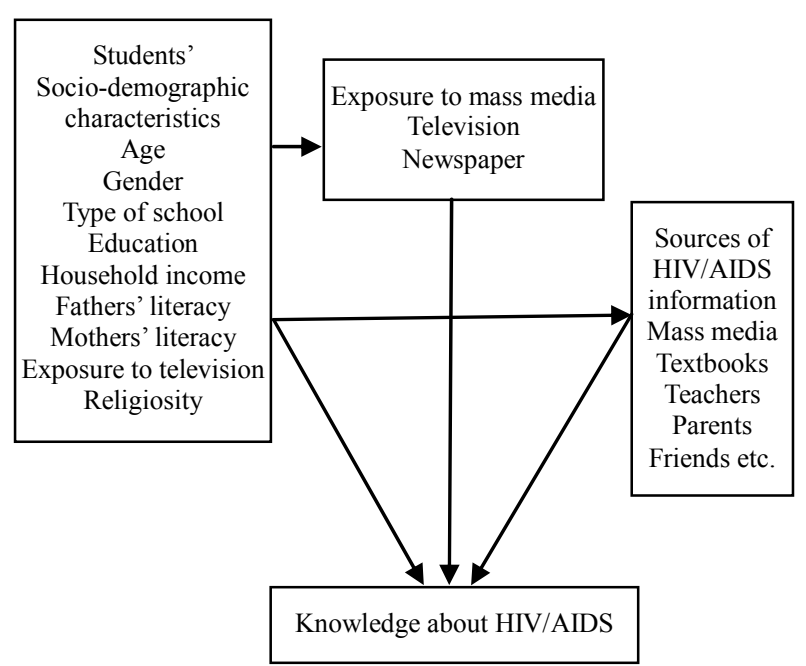

Figure 1. Conceptual framework of the study (self-designed). 
of the scores was used as a composite score ranging from 0 to 12 with a higher score indicating a greater level of knowledge about HIV/AIDS. Based on the pooled scores for each respondent, they have been classified into three groups, viz., poor knowledge ( 0 - 4), good knowledge (5 - 8), and very good knowledge (9 or more). Cronbach's alpha coefficient was used to measure the internal consistency of the twelve items defining the dependent variable, knowledge about HIV/AIDS. These twelve questions demonstrated good internal consistency (Cronbach's alpha $=0.80)$. Cronbach's alpha is the most common measure of internal consistency ("reliability"). It is most commonly used when we have multiple Likert questions in a survey/questionnaire that forms a scale and we wish to determine if the scale is reliable [18].

\subsection{Sampling Design}

Multistage random sampling design was used to identify the students. At first, we selected eight secondary schools from four divisions namely Dhaka, Khulna, Barisal, and Rajshahi in Bangladesh. These four divisions were chosen out of seven randomly. After collecting the lists of secondary schools of each division from Bangladesh Bureau of Educational Information and Statistics (BANBEIS) office, we selected equal number of schools (four schools from urban and four from rural area) randomly for the purpose of the study. Finally, 48 students aged 11 - 17 years were chosen using lottery method from the student list of each school. Therefore, each participant had the same probability of being chosen. Once the desired 48 respondents from each school were selected, the investigators moved to next sampled school. In total, 384 secondary school students of grade six to ten from the eight sampled schools were chosen using Fisher's formula. In this study, $10-12$ percent of the students refused to participate in some of the classes. This was taken into account by moving to the next student until the desired sample was obtained.

\subsection{Data Analysis}

All data were entered using the Statistical Package for the Social Sciences (SPSS) software (Version 16). The analysis was done at three stages: descriptive statistics, bivariate analyses and multivariate logistic regression. In this study, descriptive statistics were used to examine the students' socio-demographic characteristics, exposure to mass media, knowledge about HIV/AIDS, and its sources of knowledge. The scores on the socio-demographic characteristics, exposure to mass media, knowledge about HIV/AIDS, and its sources of knowledge were in frequency and percentage form of categorized responses. In the process of analysis, relationships supporting or refusing the pre-formulated hypothesis were subjected to sta- tistical tests of significance. Test statistics like Pearson Chi-square and Cramer's V were used to measure the magnitude/strength of relationships among the variables. In addition, a binary logistic regression model was employed to explore the possible effects of each predictor variable on knowledge about HIV/AIDS.

\section{Results and Discussion}

Of 380 secondary school students who participated in the current study, 55.26 percent of the students were above 14 years of age and their ages ranged from 11 to 17 years with a mean of 13.87 years and a standard deviation of 2.001. The study also found that male students constituted more than half of the respondents (52.08\%). Again, approximately one-fifth of the students $(21.35 \%)$ were studying in grade six whereas a little less than one-fifth of them $(18.75 \%)$ were in grade ten. The percentage of grade six students was slightly bigger than those of other grades. Not surprisingly, most of the respondents $(75.53 \%)$ were the followers of Islam and irrespective of religious affiliation, a little more than half of the students (53.65\%) performed religious activities every day.

Parents' literacy is a significant determinant of students' knowledge about HIV/AIDS. This study demonstrated that an overwhelming number of students' fathers (92.11\%) were literate whereas for mothers it was 90.53 percent, indicating fathers were more literate than mothers. Their mean family size was 5.23 and more than half of the students' $(51.84 \%)$ family incomes were less than 15,000 taka monthly. Urban school students, which constituted half of the sample, mostly belonged to the higher income group.

\subsection{Students' Exposure to Mass Media}

This study assessed exposure to media by asking students whether they watch television (TV), and read newspaper. However, viewership of TV and readership of newspaper depend on the availability of, and access to, those either at home or in the neighborhood. This study found that around three-fourths of the students $(75.78 \%)$ watched television whereas 38.28 percent students replied that they read newspapers. Again, TV viewership and newspaper readership was sharply higher among the students of urban schools. Moreover, there was a great variation among them with regard to frequency of watching television and reading newspaper-around three-fourths of the students $(76.05 \%)$ said that they watched television daily whereas only a negligible number of the respondents $(10.26 \%)$ reported that they read newspaper regularly.

\subsection{Sources of HIV/AIDS Information}

The multiple responses of the main sources of information about HIV/AIDS were the mass media, with televi- 
sion $(65 \%)$ ranking the first, followed by newspaper $(60 \%)$, and radio $(53 \%)$. These findings are consistent with those of the studies carried out by Shirin and Ahmed (2007) [11]; Islam et al. (2002) [19]; Asekun-Olarinmoyem et al. (2011) [20]; Khan (2002) [13]; Oyo-Ita et al. (2005) [21]; Lal et al. (2000) [15]. The second important source of HIV/AIDS information was textbooks (58\%), followed by teachers $(47 \%)$, parents $(45 \%)$, and friends $(43 \%)$. Messages written on vehicles $(37 \%)$, seminar $(8 \%)$ were the least-reported sources of information regarding HIV/AIDS.

\subsection{Students' Knowledge about HIV/AIDS}

Figure 2 displayed that a substantial number of students (36.98\%) had a very good knowledge about HIV/AIDS. This finding of this study was moderately consistent with the findings of the studies carried out by Uddin et al. (2010) [10] on Bangladeshi adolescents and UNESCO (2007) [22] on the students in Cameroon. The latter study found that 48 percent of the respondents in Cameroon had good knowledge about HIV/AIDS. The study which was conducted on the adolescents of Bangladesh displayed that half of the adolescents had fair level of knowledge regarding HIV/AIDS. By contrast, this finding of the current study was not consistent with the findings of the studies conducted by Shirin and Ahmed (2007) [11] and Amanullah and Huda (2012) [23]. According to their study, a very few respondents were found to have a good understanding of AIDS. Again, the results of this crosssectional study demonstrated that a little more than onethird of the students (34.37\%) had good knowledge while around 28 percent students fell within the category of poor knowledge (Figure 2).

The level of knowledge was determined by the students' answers to twelve statements regarding HIV and AIDS (Table 1). Given below are the separate answers to each of those statements.

\subsection{Association between Selected Socio-Demographic Factors and Knowledge about HIV/AIDS}

Table 2 showed the evidence of clear relationships between a set of socio-demographic factors and students' level of knowledge about HIV/AIDS. The findings of the study indicated that knowledge about HIV/AIDS was significantly associated with some socio-demographic variables, and the results indicated that older respondents $\left(\chi^{2}=18.90, p<0.01\right)$ and male students $\left(\chi^{2}=4.36, p<\right.$ $0.01)$ displayed higher level of knowledge about HIV/ AIDS. These associations were consistent with the findings of the report of Ministry of Health and Family Welfare, Bangladesh (2009) [24] and those of the study conducted by Uddin et al. (2010) [10] among the adolescents

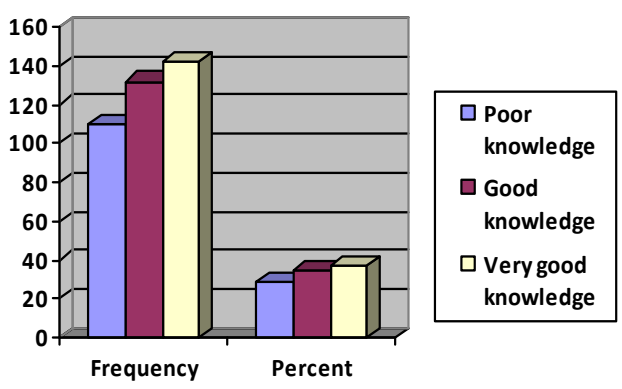

Figure 2. Students' knowledge about HIV/AIDS.

Table 1. Students' knowledge about HIV/AIDS.

\begin{tabular}{|c|c|c|c|}
\hline \multirow{2}{*}{$\begin{array}{l}\text { Statement on HIV/AIDS with } \\
\text { regard to Knowledge }\end{array}$} & \multirow{2}{*}{ Response } & \multicolumn{2}{|c|}{ Correct answer } \\
\hline & & Frequency & Percent \\
\hline $\begin{array}{l}\text { HIV/AIDS is a great threat } \\
\text { for Bangladesh }\end{array}$ & True & 328 & 85.42 \\
\hline $\begin{array}{l}\text { HIV/AIDS has a positive } \\
\text { relation with STDs }\end{array}$ & True & 238 & 61.98 \\
\hline $\begin{array}{l}\text { A person can get AIDS by } \\
\text { kissing someone on the } \\
\text { mouth or through hugging }\end{array}$ & False & 322 & 83.85 \\
\hline $\begin{array}{l}\text { People living with HIV/AIDS } \\
\text { should keep separate from others }\end{array}$ & False & 261 & 67.97 \\
\hline $\begin{array}{l}\text { A pregnant woman who has } \\
\text { AIDS can transmit it to her baby }\end{array}$ & True & 186 & 48.44 \\
\hline $\begin{array}{l}\text { Mosquito bites is one possible } \\
\text { cause of infection }\end{array}$ & False & 316 & 82.29 \\
\hline $\begin{array}{l}\text { Most people who get AIDS } \\
\text { usually die from the disease }\end{array}$ & True & 248 & 64.58 \\
\hline AIDS is a viral infectious disease & True & 181 & 47.14 \\
\hline $\begin{array}{l}\text { One can get HIV infection having } \\
\text { unprotected sex only one time }\end{array}$ & True & 182 & 47.40 \\
\hline AIDS is a curse from God & False & 327 & 85.16 \\
\hline AIDS is a foreign disease & False & 249 & 64.84 \\
\hline $\begin{array}{l}\text { AIDS can be cured through } \\
\text { herbal treatment }\end{array}$ & False & 241 & 62.76 \\
\hline
\end{tabular}

in Bangladesh. The important factor of the association between age and knowledge about HIV/AIDS in this study was that older students showed higher level of curiosity to learn about the taboo subject and this, in turn, encouraged them to discuss HIV/AIDS with each other. Moreover, results of this cross-sectional study showed that type of school and household income were seen to be significantly related to knowledge about HIV/AIDS. Data showed that students of urban school $\left(\chi^{2}=9.16, p<\right.$ $0.01)$ and those having high household income $(V=0.77$, $p<0.05$ ) showed greater tendency to have high knowledge about HIV/AIDS and these associations were moderately consistent with the findings of the studies accomplished by Lal et al. (2000) [15] and Tee and Huang (2009) [17]. The crucial reasons behind these types of association were that students of urban school and those 
Table 2. Summary table of chi-square and Cramer's V values on level of knowledge regarding HIV/AIDS by sociodemographic characteristics.

\begin{tabular}{cc}
\hline $\begin{array}{c}\text { Socio-demographic } \\
\text { characteristics }\end{array}$ & Level of knowledge about HIV/AIDS \\
\cline { 2 - 2 } Age & $\chi^{2}=18.90^{* *}, \mathrm{df}=4$ \\
Gender & $\chi^{2}=4.36^{* *}, \mathrm{df}=1$ \\
Type of school & $\chi^{2}=9.16^{* *}, \mathrm{df}=2$ \\
Level of education & $V=0.45$ \\
Household income & $V=0.77^{*}$ \\
Fathers' literacy & $\chi^{2}=9.48^{* *}, \mathrm{df}=3$ \\
Mothers' literacy & $\chi^{2}=12.91^{* * *}, \mathrm{df}=5$ \\
Watching television & $\chi^{2}=16.21^{* * *}, \mathrm{df}=7$ \\
Religiosity & $\chi^{2}=8.56, \mathrm{df}=4$ \\
\hline${ }^{* * *} p=0.001 ;{ }^{* *} p=0.01 ;{ }^{*} p=0.05$. &
\end{tabular}

having higher household income had greater degree of exposure to mass media including television and newspaper. Furthermore, literacy, either of their fathers $\left(\chi^{2}=\right.$ $9.48, p<0.01)$ or of their mothers $\left(\chi^{2}=12.91, p<0.001\right)$, had a linear and positive relationship with having knowledge about HIV/AIDS. Similar association was found in case of watching television $\left(\chi^{2}=16.21, p<0.001\right)$, that is, students who watched television regularly were more likely to have higher degree of knowledge about HIV/ AIDS (Table 2).

\subsection{Binary Logistic Regression Analysis for Knowledge about HIV/AIDS}

Age of the respondents, their mothers' literacy, and watching television emerged as important determinants of knowledge about HIV/AIDS in binary logistic regression analysis as presented in Table $\mathbf{3}$. The dependent variable considered in this model was knowledge about HIV/ AIDS and was coded as dummy; 1 (high knowledge) and 0 (low knowledge). Results of the binary logistic regression analysis demonstrated that older students were almost two times more likely to have higher degree of knowledge about HIV/AIDS (OR $=1.923, p<0.05$ ) compared with younger respondents. This finding was moderately consistent with that of the study done by Rahman et al. (2009) [12], who showed that older adolescents aged 15 - 19 years were significantly more likely to know about AIDS than their younger counterparts (OR $=1.4$ ).

With respect to mothers' literacy, students having literate mothers had higher odds ratio of having higher degree of knowledge about HIV/AIDS (OR $=3.579, p<$ 0.01 ) compared with those who had illiterate mothers. This model also found watching television as one of the
Table 3. Results of logistic regression analysis on knowledge about HIV/AIDS.

\begin{tabular}{|c|c|c|c|c|}
\hline $\begin{array}{l}\text { Determinants of } \\
\text { knowledge }\end{array}$ & Coefficient & $\begin{array}{l}\text { Standard } \\
\text { error }\end{array}$ & Significance & $\begin{array}{l}\text { Odds } \\
\text { ratio }\end{array}$ \\
\hline \multicolumn{5}{|l|}{ Age (in years) } \\
\hline$<14$ & $0.592^{*}$ & 0.151 & 0.017 & 1.923 \\
\hline \multicolumn{5}{|l|}{$\begin{array}{l}\text { Gender } \\
\text { Male }\end{array}$} \\
\hline Female & 1.547 & 0.376 & 0.146 & 3.579 \\
\hline \multicolumn{5}{|l|}{ Type of school } \\
\hline Rural school & 0.451 & 0.680 & 0.075 & 0.464 \\
\hline \multicolumn{5}{|l|}{$\begin{array}{c}\text { Father's literacy } \\
\text { Literate }\end{array}$} \\
\hline Illiterate & -0.566 & 0.436 & 0.194 & 1.762 \\
\hline \multicolumn{5}{|l|}{$\begin{array}{c}\text { Mother's literacy } \\
\text { Literate }\end{array}$} \\
\hline Illiterate & $.566^{* *}$ & 0.436 & 0.003 & 3.579 \\
\hline \multicolumn{4}{|c|}{ Household income (in taka) } & \\
\hline$>15,000$ & -0.621 & 0.648 & 0.338 & 1.861 \\
\hline \multicolumn{5}{|l|}{ Watching television } \\
\hline Hardly & $2.75^{* *}$ & 0.289 & 0.002 & 4.078 \\
\hline Constant & 1.605 & 2.603 & 0.538 & 4.976 \\
\hline
\end{tabular}

Cox \& Snell $R^{2}=0.231$

$\mathrm{N}=384$ Hosmer and Lemeshow Test: $\chi^{2}=16.99, \mathrm{df}=8, p=0.005$

${ }^{* *}$ and ${ }^{*}$ are significant levels at $1 \%$ and $5 \%$, respectively.

significant predictors of knowledge about HIV/AIDS, that is, students who watched television regularly were significantly more likely to have high knowledge about HIV/AIDS (OR $=4.078, p<0.01)$ as compared with those who hardly watched television, a vital component of promoting awareness regarding HIV/AIDS [25]. However, there were no statistically significant relationships between knowledge about HIV/AIDS and some independent factors like gender, type of school, fathers' literacy, and household income in this model (Table 3).

\section{Conclusion}

Despite the current low prevalence, HIV/AIDS is increasingly being viewed as a major threat for the development of Bangladesh since it can weaken economic growth, educational institutions, governance, and social stability etc. Recognizing this threat, Government of Bangladesh in association with PIACT Bangladesh, a local NGO, included a chapter on HIV/AIDS in the textbooks of secondary school students in 2007 [26] with a view to providing fundamental knowledge of the epidemic. HIV/AIDS knowledge is considered as the most important weapon to fight against HIV/AIDS [27] and all efforts to curb its spread will be in vain [28] unless adolescents including 
students are knowledgeable about it. Therefore, this crosssectional study assessed the secondary school students' level of knowledge about HIV/AIDS. This exploratory study clearly showed students' high level of knowledge regarding HIV/AIDS and some modes such as television, newspaper, textbooks, teachers etc. of disseminating HIV/AIDS information. The bivariate results of the current study indicated that male students, urban school students, older students, students having high household income, students with literate parents, and those who watched television regularly demonstrated greater propensity to have higher degree of knowledge about HIV/ AIDS. Moreover, results of the binary logistic analysis displayed that older students, students having literate mothers and those who watched television regularly were more likely to have higher degree of knowledge about HIV/AIDS. Watching television was found as the best single predictor of knowledge about HIV/AIDS. Our findings of the current study suggest that more information on HIV/AIDS should be included in the textbooks of secondary school students in addition to teachers' training that can facilitate the teaching process of this taboo subject. Finally, findings of this study may be of significant value for educators, researchers, health professionals, teachers, counselors, and government officials in the Ministry of Education in Bangladesh.

\section{Acknowledgements}

The authors would like to express their heartfelt gratitude to Abeer Noor, lecturer of Green University, Bangladesh for her guidance and suggestions. The authors are also grateful to Lipi Akhter for her cordial assistance in field work.

\section{REFERENCES}

[1] E. Taher and R. Abdelhai, "Nurses' Knowledge, Perceptions, and Attitudes towards HIV/AIDS: Effects of a Health Education Intervention on Two Nursing Groups in Cairo University," Journal of Public Health and Epidemiology, Vol. 3, No. 4, 2011, pp. 144-154.

http://www.academicjournals.org/jphe/PDF/pdf2011/Apri 1/Taher\%20and\%20Abdelhai.pdf

[2] UNAIDS, "UNAIDS Report on the Global AIDS Epidemic," 2012.

http://www.unaids.org/en/media/unaids/contentassets/doc uments/epidemiology/2012/gr2012/20121120_UNAIDS_ Global_Report_2012_en.pdf

[3] A. S. M. Amanullah and M. N. Huda, "Study on the Situation of Children of Sex Workers in and around Daulatdia Brothel," Save the Children International, Dhaka, 2012.

[4] E. L. Fulton, N. Kamal, S. M. Ahmed and M. I. Khan, "AIDS Knowledge in Rural Bangladesh," BRAC-ICDDR, Dhaka, 1998.
http://www.bracresearch.org/workingpapers/Working_Pa per_21.pdf

[5] M. N. Huda, "AIDS Education through Formal Curriculum and Texts in Bangladesh: A Formative Study," Master's Thesis, University of Dhaka, Dhaka, 2011.

[6] Ministry of Health and Family Welfare, "National HIV Serological Surveillance, 2011 Bangladesh," 2011. http://www.aidsdatahub.org/dmdocuments/HSS 9th_roun d_2011.pdf

[7] UNAIDS, “Country Progress Report: Bangladesh,” 2012. http://www.unaids.org/en/dataanalysis/knowyourresponse /countryprogressreports/2012countries/ce_BD_Narrative Report\%5B1\%5D.pdf

[8] N. I. Mondal, H. Takaku, Y. Ohkusa, T. Sugawara and N. Okabe, "HIV/AIDS Acquisition and Transmission in Bangladesh: Turning to the Concentrated Epidemic," Japanese Journal of Infectious Diseases, Vol. 62, No. 2, 2009, pp. 111-119.

[9] UNAIDS, "Position Statement on Condoms and HIV Prevention," 2004.

http://data.unaids.org/pub/BaseDocument/2009/20090318 _position_paper_condoms_en.pdf

[10] M. A. Uddin, S. Isaramalai and J. Thassari, "Knowledge and Attitude regarding HIV/AIDS Prevention among Adolescents in Bangladesh," Paper Presented at the 2nd International Conference on Humanities and Social Sciences, Faculty of Liberal Arts, Prince of Songkla University, 2010.

[11] S. Shirin and S. Ahmed, "Knowledge of AIDS among the Adolescent Students of Two selected Colleges of Dhaka City," Ibrahim Medical College Journal, Vol. 1, No. 2, 2007, pp. 5-8.

http://www.banglajol.info/index.php/IMCJ/article/downlo $\mathrm{ad} / 2897 / 2404$

[12] M. M. Rahman, M. Kabir and M. Shahidullah, “Adolescent Knowledge and Awareness about HIV/AIDS and Factors Affecting Them in Bangladesh," Journal of Ayub Medical College Abbottabad, Vol. 21, No. 2, 2009, pp. 3-6. http://www.ayubmed.edu.pk/JAMC/PAST/21-3/Mizan.pdf

[13] M. A. Khan, "Knowledge on AIDS among Female Adolescents in Bangladesh: Evidence from the Bangladesh Demographic and Health Survey Data," Journal of Health, Population and Nutrition, Vol. 20, No. 2, 2002, pp. 130137. http://www.ncbi.nlm.nih.gov/pubmed/12186193

[14] M. Rahman, I. M. Wali-ul and T. Fukui, "Knowledge and Practices about HIV/AIDS among the Commercial Sex Workers in Bangladesh," Journal of Epidemiology, Vol. 8, No. 3, 1998, pp. 181-183. http://www.ncbi.nlm.nih.gov/pubmed/9782675 http://dx.doi.org/10.2188/jea.8.181

[15] S. S. Lal, R. S. Vasan, P. S. Sarma and K. R. Thankappan, "Knowledge and Attitudes of College Students in Kerala towards HIV/AIDS, Sexually Transmitted Diseases and Sexuality," The National Medical Journal of India, Vol. 13, No. 5, 2000, pp. 231-236. http://www.ncbi.nlm.nih.gov/pubmed/11190050

[16] L. P. Wong, C. K. L. Chin, W. Y. Low and N. Jaafar, 
"HIV/AIDS-Related Knowledge among Malaysian Young Adults: Findings from a Nationwide Survey," Journal of the International AIDS Society, Vol. 10, No. 148, 2008. http://www.ncbi.nlm.nih.gov/pmc/articles/PMC2757394/

[17] Y. Tee and M. Huang, "Knowledge of HIV/AIDS and Attitudes towards People Living with HIV among the General Staff of a Public University in Malaysia," Journal of Social Aspects of HIV/AIDS Research Alliance, Vol. 6, No. 4, 2009, pp. 179-187.

http://www.ncbi.nlm.nih.gov/pubmed/20485857

http://dx.doi.org/10.1080/17290376.2009.9724946

[18] D. George and P. Mallery, "SPSS for Windows Step by Step: A Simple Guide and Reference," Allyn \& Bacon, Boston, 2003.

[19] M. T. Islam, G. Mostafa, A. U. Bhuiya, S. Hawkes and A. Francisco, "Knowledge on, and Attitude toward, HIV/ AIDS among Staff of an International Organization in Bangladesh," Journal of Health, Population and Nutrition, Vol. 20, No. 3, 2002, pp. 271-278. http://www.ncbi.nlm.nih.gov/pubmed/12430765

[20] E. O. Asekun-Olarinmoye, F. O. Olajide and I. O. AsekunOlarinmoye, "HIV/AIDS Preventive Measures among InSchool Adolescents in a Sub-urban Community in Southwestern Nigeria," The Journal of Life and Physical Sciences, Vol. 4, No. 1, 2011, pp. 81-96.

http://www.google.com.bd/url?sa=t\&rct=j\&q=\&esrc=s\&s ource $=$ web \&cd $=1 \& v e d=0$ CCoQFjAA\&url $=$ http $\% 3 \mathrm{~A} \% 2 \mathrm{~F}$ $\% 2$ Fwww.actasatech.com $\% 2$ Fdownload.php\%3Ffile $\% 3 \mathrm{D}$ Journal-128.pdf\&ei $=$ X2fmUYKeGIizrAelxYHYCw \& usg =AFQjCNFqmjzEFRYo1E49a-knxDdvJCKLJg\&bvm $=$ bv.49405654,d.bmk

[21] A. E. Oyo-Ita, B. M. Ikpeme, A. J. Etokidem, J. B. Offor, E. O. Okokon and S. J. Etuk, "Knowledge of HIV/AIDS among Secondary School Adolescents in Calabar-Nigeria," Annals of African Medicine, Vol. 4, No. 1, 2005, pp. 2-6.

https://tspace.library.utoronto.ca/bitstream/1807/5038/1/a m05002.pdf

[22] UNESCO, "Review of Sex, Relationships and HIV Education in Schools," 2007.

http://unesdoc.unesco.org/images/0016/001629/162989e. pdf

[23] A. S. M. Amanullah and M. N. Huda, "Commercial Sex and Vulnerability to HIV Infection: A Study among the Children of Sex Workers in Tangail Brothel," In: D. M. Sabet, T. Rahman and S. Ahmad, Eds., Sex Workers and Their Children in Bangladesh: Addressing Risks and Vulnerabilities, University of Liberal Arts Bangladesh and Action Aid Bangladesh, Dhaka, 2012, pp. 59-81. http://www.ulab.edu.bd/CSD/publications/Leadr_chapter $\% 204 . p d f$

[24] Ministry of Health and Family Welfare, "Bangladesh Demographic and Health Survey 2007," 2009. http://www.unicef.org/bangladesh/BDHS2007_Final.pdf

[25] L. K. Ackerson, S. Ramanadhan, M. Arya and K. Viswanath, "Social Disparities, Communication Inequalities, and HIV/AIDS-Related Knowledge and Attitudes in India," AIDS Behavior, Vol. 16, No. 7, 2012, pp. 2072-2081. http://dx.doi.org/10.1007/s10461-011-0031-y

[26] PIACT Bangladesh, "Rapid Assessment of the Role of Teachers' Training in HIV/AIDS Prevention in Two Selected Districts in Bangladesh,” 2009.

[27] T. T. Fako, L. W. Kangara and N. Forcheh, "Predictors of Knowledge about HIV/AIDS among Young People: Lessons from Botswana," Journal of AIDS and HIV Research, Vol. 2, No. 6, pp. 116-130. http://www.academicjournals.org/jahr/PDF/Pdf2010/Sept /Fako\%20et\%20al.pdf

[28] P. Aggleton, "Global Priorities for HIV/AIDS Intervention Research," International Journal of STD and AIDS, Vol. 7, No. 2, 1996, pp. 13-16. http://dx.doi.org/10.1258/0956462961917726 